\title{
A organização da Instrução Pública Municipal na década de 1920 no Município de Bagé/RS
}

\begin{abstract}
Alessandro Carvalho Bica
Resumo: Este artigo analisa a organização da Educação Primária Pública no município de Bagé durante o final da década de 1920, sob a ótica e os preceitos dos políticos republicanos gaúchos. Neste sentido, os discursos políticos e as ações administrativas no transcorrer da década de 1920 possibilitaram certa centralidade à educação nas proposições dos governos republicanos gaúchos, logo, ela passou a ser concebida como um direito do cidadão e como uma necessidade para o progresso social e cultural da nação. Sendo assim, a educação tornou-se um dos principais instrumentos da regeneração dos cidadãos, como também um elemento fundamental na execução das reformas sociais, responsáveis pelo advento da modernidade republicana.
\end{abstract}

Palavras-chave: História da Educação de Bagé. Primeira República. Organização de Educação Municipal.

\section{The organization of Public Municipal Instruction in the 1920s in the Bagé/RS}

\begin{abstract}
This article analyzes the organization of Public Primary Education in the city of Bage during the late 1920s, the perspective and the precepts of the gauchos Republican politicians. In this sense, the political speeches and administrative actions in the course of the 1920s allowed centrality of education in the propositions of the gauchos Republican administrations, so she began to be conceived as a citizen's right and a necessity for social progress and cultural nation. Therefore, education has become a major instrument of regeneration of citizens, but also a key element in the implementation of social reforms, responsible for the advent of republican modernity.
\end{abstract}

Keywords: History of Education Bagé. First Republic. Organization of Municipal Education. 
BICA, Alessandro Carvalho. A organização da Instrução Pública Municipal na década de 1920 no Município de Bagé/RS.

\section{A administração de Carlos Cavalcanti Mangabeira (1925-1929)}

A condução de Carlos Cavalcanti Mangabeira à Intendência Municipal de Bagé no ano de 1925 deve ser compreendida no contexto dos reflexos políticos e administrativos ocorridos na última década da Primeira República. As conjecturas oriundas da Pacificação de 1923 no Estado do Rio Grande do Sul e Reforma da Lei Orgânica Municipal em 1924 provocaram uma nova configuração dentro do Partido Republicano Bajeense nos últimos anos da década de 1920.

Neste sentido, é interessante perceber que a eleição de Carlos Cavalcanti Mangabeira para o pleito municipal, representa o refortalecimento do princípio da hegemonia partidária do PRR bajeense após a distensão política ocorrida com a assinatura do Pacto de Pedras Altas, esse movimento ocorreu simultaneamente na capital do Estado, Porto Alegre, como afirma Bakos (2007, p. 195), sobre a eleição do intendente republicano Otávio Rocha no ano de 1925:

\footnotetext{
À luz do pensamento de Gramsci, sabe-se, hoje, que é preciso, quando se verifica uma crise hegemônica, apresentarem-se líderes e projetos novos. Na prática, essa foi à atitude do PRR, escolhendo Otávio Rocha à execução de remodelação da cidade [...]. Consciente da importância de seu papel e do dever procurou-se cercar de técnicos especializados, aumentando, em muito, a burocracia do governo municipal [...] Uma das medidas prioritárias do novo intendente foi organizar o sistema [...] para, a partir daí, fazer as reformas $[\ldots]$.
}

A leitura da citação de Bakos (2007) nos ajuda também a compreender a postura ideológica, política e administrativa que Carlos Cavalcanti Mangabeira iria imprimir na condução da Intendência Municipal de Bagé após o ano de 1925. Ao que tudo indica, Mangabeira assumiu uma postura austera em relação aos princípios positivistas na condução de sua gestão administrativa. Sendo assim, ao assumir a Intendência municipal, Mangabeira manifestou seu interesse em regenerar as instituições políticas e administrativas, buscar a saúde financeira do município e preconizar a responsabilidade fiscal da administração pública.

Neste sentido, Carlos Cavalcanti Mangabeira guiou sua administração pela filosofia positivista, de governar pela ordem e pelo desenvolvimento do progresso das coisas públicas e privadas preconizada pelos republicanos, como afirma Corsetti (1998, p. 95): “a perspectiva reformadora de Augusto Comte foi assumida amplamente pelos republicanos rio-grandenses, desde a concepção relativa às bases cientificas da nova sociedade, [...] chegando até ao campo educacional". 
BICA, Alessandro Carvalho. A organização da Instrução Pública Municipal na década de 1920 no Município de Bagé/RS.

Portanto, Carlos Cavalcanti Mangabeira procurou buscar em sua gestão um modelo de reorganização administrativa em termos urbanos e educacionais. Apesar dos esforços empreendidos e dos avanços atingidos na gestão de Martim Tupy Silveira (1914-1925) no remodelamento urbano e no avanço educacional na cidade de Bagé, o município ainda carecia de um sistema organizado em relação às questões da administração municipal, isto é, um novo Código de Posturas Municipais.

$\mathrm{Na}$ perspectiva de reorganizar o sistema e o espaço urbano da cidade de Bagé, a administração municipal mandou publicar uma série de Editais e Atos municipais nos jornais da cidade entre os meses de abril e agosto do ano de 1925, entre eles, destacam-se os editais da Diretoria de Obras, da Seção de Águas e Esgotos, do Tesouro Municipal e da Circulação de Veículos na cidade.

Compreendemos que estas legislações fazem parte de um conjunto de normas que determinavam regras de comportamento, convívio e civilidade para a comunidade bajeense, demonstrando a disposição da Intendência Municipal em assegurar a ordem e projetar os discursos da modernidade da Primeira República na cidade de Bagé.

Portanto, entende-se que estas regras estabelecidas pela administração municipal complementavam o Código de Posturas Municipal, com um firme propósito de manter a segurança publica e resolver problemas relacionados com a saúde pública, como adverte Weber (1992, p.10): "nos municípios gaúchos, as posturas eram uma legislação específica, que atendiam as necessidades regionais e que atingiam o dia a dia da população".

Em relação aos vários editais publicados nos periódicos da cidade, o jornal Correio do Sul de 18 de abril de 1925 traz a seguinte notícia:

Intendência Municipal - Estao sendo publicados noutro logar desta folha, os seguintes editaes da Intendência Municipal, para os quaes chamamos a attenção dos interessados:

- da sub-intendencia do $1^{\circ}$ districto, referente ao código de posturas municipaes em vigor;

- da secretaria do Thesouro, prorrogando até ao dia 30 do mez corrente, o prazo para o pagamento de todos os impostos municipaes;

- da secção de aguas e exgottos, sobre o desperdício d'agua pelos consumidores;

- da Diretoria de Obras Publicas, sobre o deposito de materiaes na rua, etc.;

- da sub-intendencia do $1^{\circ}$ districto, regulamentando o transito de vehiculos (CORREIO DO SUL, 1925, p. 2).

Através destes vários códigos de condutas, percebe-se que o início da gestão de Carlos Cavalcanti Mangabeira priorizou a sistematização do controle administrativo da cidade de Bagé, 
bem como a organização das posturas públicas e particulares na região mais central da cidade. Ademais, foram também observadas medidas de embelezamento da cidade, como o plantio de árvores $^{1}$ no centro mais urbano do município.

Entre os vários editais publicados nos jornais da cidade, merece destaque o Ato $\mathrm{n}^{\mathrm{o}} 305$ de 17 de agosto de 1925, que aprovava o Regulamento de Higiene da cidade:

O intendente municipal de Bagé, no uso de attribuições legaes, e, considerando que a hygiene por suas leis e evoluções actuais, constitue uma das grandes preoccupações das sociedades adeantadas; considerando que da observancia fiel dos seus preceitos redunda um grande beneficio para todos, tanto sob o ponto de vista moral, como sob o ponto de vista physico; [...]; considerando que, após a extincção pelo governo do Estado, do cargo de delegado de hygiene, este logar nunca mais foi provido; considerando, porém, que apezar de seu grão de cultura, Bagé não comporta por enquanto todas as rigorosas medidas de hygiene absoluta; Resolve approvar o seguinte regulamento, que attende ás exigencias mais gerais e inadiaveis de hygiene particular e publica, elaborado pelo respectivo director. Bagé, 17 de agosto de 1925. Carlos Cavalcanti Mangabeira (O DEVER, 1925, p. 1, grifo nosso).

O texto do Ato da Higiene Municipal aprovado pela Intendência demonstra claramente as preocupações com a higiene pública, com o controle das epidemias, com os benefícios morais e físicos da cidade moderna, e, por outro lado, perpetuava os discursos de ordem e de controle da sociedade para o bom andamento da cidade. Sendo assim, organizar e regulamentar a cidade também significava inibir a ação de indivíduos que poderiam desafiar o poder do Estado, como afirma Silva (1997, p. 147):

Limpar a cidade significa também organizar os mecanismos institucionais capazes de garantir a continuidade do sistema social. A delinqüência precisa ser inibida, ela polui a vida nas cidades e desafia o poder do Estado. É necessário limpar através da higiene física e espiritual, moralizar o corpo e a alma do indivíduo.

As mudanças iniciadas no início da gestão de Mangabeira continuam a ser executadas nos anos seguintes, porém com uma frequência menor do que no ano de 1925. Entretanto, dentre estas mudanças destacam-se efetivamente aquelas relacionadas à Diretoria de Obras Públicas e da Repartição Central da Polícia Administrativa que tinham relação direta com o Código de Posturas Municipais. Em relação a estes Editais, destacamos:

\footnotetext{
${ }^{1}$ Nas edições do jornal Correio do Sul de 07 de junho de 1925,15 de julho de 1925 e 02 de agosto de 1925 , foram noticiadas, respectivamente: a substituição das árvores das ruas centrais, entre elas, a Rua 07 de setembro e a Rua Marechal Floriano; O ofício do Intendente de Bagé dirigido ao Intendente Municipal, Augusto Simões Lopes, requerendo mudas de árvores do Horto Municipal de Pelotas e o plantio das árvores na cidade de Bagé. As árvores plantadas na administração de Carlos Mangabeira no ano de 1925 fazem parte do patrimônio histórico e cultural da cidade na atualidade.
} 


\section{Edital - Diretoria de Obras Publicas}

De ordem do senhor intendente, faço publico que de accôrdo com os artigos abaixo transcriptos do Codigo de Posturas Municipaes, é expressamente prohibido:

- Art. $60^{\circ}$ - Levantar andaimes sem licença, não os desmanchar, quando fôr intimado, ou conserval-os em estado que ameace a segurança dos operarios e do transito publico;

- Art. $62^{\circ}$ - Fazer escavações nas ruas e praças.

Bagé, 20 de março de 1926 (CORREIO DO SUL, 1926, p. 2).

Edital - Repartição Central da Policia Administrativa

De ordem do senhor intendente, faço publico que de accôrdo com os artigos abaixo transcriptos do Codigo de Posturas Municipaes, é expressamente prohibido:

- Art. $58^{\circ}$ - A pessoa conservar nas ruas ou praças qualquer objecto que prejudique o transito publico;

- Art $63^{\circ}$ - Transitar pelas calçadas ou passeios com volumes na cabeça, nos hombros ou nas mãos, que prejudiquem o transito publico;

- Art. $66^{\circ}$ - Conduzir pela cidade animaes soltos ainda que sejam mansos.

Aos infractores serão applicadas as penas da lei.

Bagé, 20 de março de 1926 (CORREIO DO SUL, 1926, p. 2).

O contexto destas reformas e do cumprimento do novo Código de Posturas Municipais se insere numa esfera onde o poder da administração municipal postulou o ideário de uma cidade progressista e republicana. Neste conjunto de mudanças ficou evidente a inspiração de Mangabeira de buscar uma sólida formação da legitimidade da Intendência na construção de uma cidade higiênica, moderna e bela.

Enfim, a administração municipal de Carlos Cavalcanti Mangabeira pautou-se pela reconfiguração da cidade nos seus mais variados aspectos, fossem eles, relacionados ao Planejamento Urbano, ao Saneamento Público, ao Controle das Finanças Municipais, ao aumento das Estradas Urbanas e Vicinais do município, como também no gerenciamento da Instrução Pública e da Educação Primária Municipal entre os anos de 1925 a 1929.

Em alusão ao primeiro aniversário da gestão de Carlos Mangabeira, o jornal O Dever, de 11 de abril de 1926, traz em seu editorial a seguinte notícia sobre as muitas mudanças ocorridas na cidade de Bagé:

Um Anno de Intenso Trabalho

Um brilhante exemplo de administração

$\mathrm{O}$ que tem sido, em 365 dias, o intelligente esforço do dr. Mangabeira a prol dos interesses de Bagé

[...]. Devia succeder a um governo que se identificara, intimamente, com o povo, num contacto permanente de doze annos de governança. Devia succeder a um governo que se popularisava, creando fundas raizes no coração do povo, pelo seu notável espírito de cordura, de tolerancia, de sentimentos confraternisadores, mais realçados nos angustiosos dias da nevrose revolucionaria. [...], que o Dr. Mangabeira tem estado inteiramente delicadamente entregue multiplas 
preoccupações do seu governo que, seja dito sem mais ardança, tem sido admirável de operosidade, despertando os mais enthusiasticos applausos da população e sendo motivo de honrosas referencias, por parte de quantos no Estado. [...], transformando Bagé num verdadeiro centro de progresso e conquistando-lhe definitivamente a honrosissima prerogativa de RAINHA DA FRONTEIRA. [...] (O DEVER, 1926, p. 1, grifo nosso).

A leitura desta notícia nos ajuda a compreender a importância política da eleição de Carlos Mangabeira ao posto de Intendente Municipal visto alusão feita ao tempo de permanência de Tupy Silveira, ex-intendente de Bagé, como também aos fatos políticos que antecederam sua eleição. Por outro lado, esta mesma notícia reafirma os avanços progressistas da administração municipal, além de promover o reconhecimento da cidade como a "Rainha da Fronteira", em função de seus aspectos geográficos, históricos e políticos.

Outro momento importante da gestão de Mangabeira em relação ao Planejamento Urbano da cidade ocorre no mês de agosto de 1926, quando a Intendência Municipal aprova o Regulamento de Veículos, promovendo assim a organização da cidade em seus aspectos modernos para a circulação de veículos de tração animal e mecanizada, como percebemos abaixo:

Acto no 326 - Approva o Regulamento de Vehiculos

O intendente municipal de Bagé, no uso de suas attribuições legais, e, considerando necessaria uma lei que regule o transito dos vehiculos, dentro dos limites urbanos; considerando que o codigo de posturas, decretado em 31 de agosto de 1899, além de ser muito deficiente, estabelece n'um capitulo, ligeiras disposições referentes unicamente a vehiculos de tracção animal; considerando que após a decretação do referido codigo, é que tomaram grande desenvolvimento os vehiculos de ttracção mechanica; Intendencia Municipal de Bagé, 14 de agosto de 1926. Carlos Cavalcanti Mangabeira (O DEVER, 1926, p. 2, grifo nosso).

A aprovação do Regulamento de Veículos possibilitou o estabelecimento de novas regras de circulação no centro urbano, visto que agora o desenvolvimento do município estava associado à modernidade. Neste sentido, é importante observar, que após a efetivação deste regulamento, foi firmado entre a Intendência Municipal e a Empresa Juvenil Bispo \& Arteche o acordo da primeira concessão de linhas de ônibus para o centro urbano da cidade de Bagé ${ }^{2}$.

\footnotetext{
${ }^{2}$ No processo empírico da pesquisa encontramos na edição do jornal O Dever de 29 de dezembro de 1926 (p. 2), a seguinte notícia: Bagé vae ter uma linha de autoomnibus. A afirmação contida na notícia, afirma que a primeira linha de "auto-omnibus" da cidade de Bagé funcionaria a partir de janeiro de 1927 com ônibus de excelentes acomodações comportando 24 pessoas, e que: O auto-omnibus, é hoje o meio de condução mais preferido, conforme se está falando na capital do Estado, onde estes carros vém fazendo concorrencia aos bondes elétricos. [...] além de economica e confortávell, é rapida e barata, sendo um grande melhoramento para a cidade (grifo nosso).
}

Quaestio, Sorocaba, SP, v. 20, n. 1, p. 91-112, abr. 2018 
BICA, Alessandro Carvalho. A organização da Instrução Pública Municipal na década de 1920 no Município de Bagé/RS.

Sobre as mudanças estruturais e os melhoramentos urbanos ocorridos nos primeiros anos da administração de Carlos Cavalcanti Mangabeira, o jornal O Dever, de 27 de janeiro de 1927, traz a seguinte notícia, da qual destacamos:

À CIDADE DE LARGAS AVENIDAS - A administração de Mangabeira cumpre galhardamente o seu programma. Vae apenas para metade do seu periodo de governamenta a actual administração de municipio de Bagé, e podemos desde já constatar a plena realização do magnífico programa do sr. d. Carlos Mangabeira, consubstanciado nestes quatro expressivos intituitos, que objetivam o brilhante esforço dos interesses públicos: instruçção, estradas, saneamento, finanças. [...] A prova está ahi, flagrante, no destino que o actual governo do municipio vae dar aos 2500 contos do empréstimo que o Estado permittiu ao municipio [...]. Esse empréstimo vae garantir um srviço hydraulico á altura das nossas necessidades, continuando, portanto, o portentoso "trabalho de Hercules" da administração do benemérito Coronel Tupy. [...], informaremos que 120 contos destina-os o orçamento á illuminação da cidade, 70 á instrucção, 250 ás obras publicas, e 250 contos á segurança urbana e rural, [...] (O DEVER, 1927, p. 1, grifo nosso).

Apesar da demonstração de operosidade da administração de Carlos Mangabeira descrita na notícia publicada do jornal O Dever, onde são aclamados os feitos do governo municipal nas questões relacionadas à modernização da cidade, como também da posição política ocupada por Mangabeira frente ao governo do Estado e no apoio as questões da municipalidade bajeense por Borges de Medeiros. Obviamente que as divergências políticas não ficaram somente no plano das ideias, mas foram explorados nos editoriais do Jornal Correio do Sul, enfatizando a posição política e ideológica de seus editores. Neste sentido, dois editorais são importantes de serem analisadas:

Olhe os Buracos, Sr. Intendente! - O estado deploravel em que se encontram certos trechos das principaes ruas da nossa urbs, leva-nos a solicitar do Sr. dr. Carlos Mangabeira, intendente do municipio, a sua attenção ao menos para os logares onde mais urgentes são reclamados reparos, em virtude de ser mais intenso ali otransito de vehiculos. Com effeito, na Avenida Sete de Setembro, uma das arterias onde maior é o movimento, [...] que, além dos inconvenientes que offerecem ao transito publico, constituem um triste, lastimável attestado de desídia para uma administração que se prese de ser zelosa e progressista [...] (CORREIO DO SUL, 1927, p. 2, grifo nosso).

A nossa Urbs - O Sr. intendente municipal determinou que as turmas de operarios da Directoria de Obras Publicas comecem, hoje, os reparos nas diversas ruas da cidade, iniciando os trabalhos na Praça da Republica e extremo norte da Avenida Sete de Setembro. Esses serviços não soffrerão interrupção, até ficar as nossas ruas em bom estado o transito (CORREIO DO SUL, 1927, p. 2, grifo nosso).

Ao observar as duas notícias acima, notamos que, apesar das críticas serem dirigidas diretamente ao Intendente e a sua administração municipal, os editores do jornal Correio do Sul, 
BICA, Alessandro Carvalho. A organização da Instrução Pública Municipal na década de 1920 no Município de Bagé/RS.

advertiam também sobre as necessidades prementes da cidade, mas por outro lado, reconheciam os avanços progressistas do município, como também, promoviam os serviços executados pela municipalidade.

Portanto, ao recuperar alguns aspectos administrativos da gestão de Carlos Cavalcanti Mangabeira percebemos que seu governo impôs uma concepção moderna do espaço urbano, um discurso privilegiado da transformação da cidade velha e colonial para uma cidade nova e republicana, na ideia da regeneração social e das práticas cotidianas. Nestes termos, Mangabeira decretou vários editais que visavam ao progresso econômico e social, além de mudar a fisionomia estrutural da cidade.

Sendo assim, esta nova visão moderna sobre a cidade apensada às ações administrativas afetaria também a elaboração das políticas públicas educacionais propostas pela gestão de Mangabeira, concordando com os preceitos estabelecidos pela filosofia e pelas práticas republicanas. Neste sentido, afirma Corsetti (2008, p. 58-59):

Portanto, a constituição da nova sociedade implicava o seu reordenamento [...] No
contraponto, o progresso teve como ingredientes a limpeza, o embelezamento das
cidades, a saúde, a reprodução da vida, a educação e, em paralelo, a disciplina, a ordem,
a produtividade, a lucratividade. Nesse contexto, a questão da educação passou a ter
uma ênfase destacada. Uma educação física, intelectual e moral da mocidade, com a
finalidade de possibilitar ao espírito todas as noções necessárias para melhor garantir a
ordem, colocou-se como central para que todos os homens tivessem consciência de seu
papel social. Em outras palavras, a educação foi vinculada à formação do cidadão
[...] (grifo nosso).

Logo, estes discursos do reordenamento da cidade, do progresso social e da vinculação da educação na formação dos cidadãos bajeenses estiveram presentes nas políticas públicas educacionais que iniciaram na gestão administrativa da intendência no ano de 1925. Neste sentido, compreende-se que Carlos Cavalcanti Mangabeira, quer seja pela sua história política, quer seja pela sua experiência pública, quer seja por sua apropriação pessoal da ideologia castilhista- borgista, foi o único político bajeense que colocou em prática a cartilha política e administrativa do PRR estadual na cidade de Bagé.

\section{A Organização da Educação Primária}

De acordo com Corsetti (1998), o projeto republicano de educação ancorava-se na expansão do ensino, na extinção do analfabetismo, na modificação dos programas curriculares, na 
BICA, Alessandro Carvalho. A organização da Instrução Pública Municipal na década de 1920 no Município de Bagé/RS.

organização e no planejamento do ensino, como também na aplicação de recursos financeiros à educação. Segunda a mesma autora "a importância da educação primária pública foi posta com insistência, sendo ela ingrediente fundamental do projeto de modernização implementado pelos positivistas no Estado" (CORSETTI, 1998, p. 171).

No Relatório Intendencial do município de Bagé do ano de 1925, encontramos a seguinte informação sobre o panorama da Educação Pública Municipal, como também sobre as futuras intenções da municipalidade em relação às questões educacionais, descritas, pelo então, Intendente Municipal, Carlos Cavalcante Mangabeira, na página inicial do documento:

Instrucção Pública - Convencido que a grandeza de um povo se aquilata principalmente pela sua instrucção e que uma das principaes funcções de uma administração é zelar pelo ensino dos seus administrados, tenho procurado cuidar com o maior desvelo e carinho d'este nobre encargo, e, assim praticando, quis que meu primeiro passo administrativo fosse concernente á instrucção publica promulgando por Acto $\mathbf{n}$. 295 de 8 Maio, o regulamento das escolas municipaes. [...]. No mesmo mez foi aberta, pela primeira vez, em Bagé, a inscripcção para o concurso ${ }^{3}$ de professores municipaes, tendo se inscripto 33 candidatos, dos quaes 25 lograram approvação. Por acto $\mathrm{n}^{\mathbf{0}} 304$ os candidatos approvados em concurso foram nomeados e localizadas as escolas [...] É de 2492 o total dos alumnos matriculados nos differentes collegios do município, assim discriminados: escolas municipaes 526, estaduaes 366, parochiaes 311, particulares 1289. Penso que o ensino primário municipal tomou outra direcção e não pouparei esforços para que a instrucção tenha a maior diffusão no município (RELATÓRIO INTENDENCIAL DO MUNICÍPIO DE BAGÉ, 1925, p. 4, grifos nossos).

A partir deste excerto do Relatório Intendencial, ponderamos, então, que as mudanças administrativas e educacionais tangenciadas pela Intendência da cidade de Bagé comecem a ocorrer efetivamente somente com a instituição do Regulamento das Escolas Municipais em 1925.

O Ato $\mathrm{n}^{\text {o }} 295$, de 08 de maio de $1925^{4}$ que estabeleceu o Regulamento das Escolas Municipais teve por objetivo unificar e controlar a Educação Primária Pública no município de

\footnotetext{
${ }^{3}$ O Edital do Concurso para o Magistério Municipal foi veiculado durante todo o mês de maio de 1925 nos jornais Correio do Sul e Dever. Para inscreverem-se no concurso, os candidatos deveriam ser brasileiros ou naturalizados, maiores de 21 anos e menores de 55 anos e atestado de boas referências, ainda no mesmo Edital se encontravam os conteúdos exigidos, "Grammatica Portugueza; Arithmetica; Geographia do Brasil e do Rio Grande do Sul e História Pátria". No Jornal Correio do Sul (1925, p. 2), foi veiculada a seguinte notícia "os exames terão inicio no dia 06 e 07 do mês entrante, sob a presidencia do respectivo inspector escolar, em uma das salas da municipalidade". O Edital de nomeação dos professores foi veiculado pelos jornais O Dever e Correio do Sul em 04 e 05 de agosto de 1925 (Grifos nossos).

${ }^{4}$ O Regulamento das Escolas Municipais de 1925 foi o primeiro regimento que atuou e legislou sobre as características administrativas, estruturais e pedagógicas das escolas municipais da cidade de Bagé, sendo publicado tem sua íntegra no jornal O Dever e no Jornal Correio do Sul na edição de 09 de maio de 1925.
}

Quaestio, Sorocaba, SP, v. 20, n. 1, p. 91-112, abr. 2018 
BICA, Alessandro Carvalho. A organização da Instrução Pública Municipal na década de 1920 no Município de Bagé/RS.

Bagé, estes termos são defendidos pelos positivistas durante toda a Primeira República. Neste sentido, o controle permanente da educação pública foi uma ferramenta defendida pelos republicanos, associada à unidade pedagógica e ao planejamento do ensino (CORSETTI, 1998).

O Regulamento das Escolas Municipais ${ }^{5}$ está subdividido em 7 (sete) capítulos. Em seu primeiro capítulo composto de 9 (nove) artigos, dedicava-se a apresentar os objetivos Da Criação e Funcionamento das escolas municipais:

Art. $1^{\circ}$ - Serão creadas tantas escolas quantas forem necessarias para a difusão do ensino no território do municipio.

Art. $2^{\circ}$ - Nos distritos rurais, no lugar em que for verificada a existencia de uma população escolar de cincoenta crianças, em condições de receber ensino, será installada uma escola. Para esse fim, o sub intendente do districto ou moradores do lugar, solicitarão, a necessidade da creação da escola.

Art. $3^{\circ}$ - As escolas que tiverem uma frequencia inferior a quinze alumnos, serão fechadas, e o professor removido para outro lugar, onde seja maior a população escolar.

Art. $4^{\circ}$ - As escolas funccionarão em casas de aluguel, arrendadas ou offerecidas pelos proprietários, dotando-as a municipalidade de todas as condicções higyenicas. [...]. O mobiliário e o material necessarios para o ensino, serão fornecidos pela intendência.

Art. $5^{\circ}$ - As escolas serão mixtas, o ensino leigo e gratuito, obedecendo ao programma organizado pela comissão de que trata o art. 10 deste regulamento.

Art. $6^{\circ}$ - É livre a matricula ás crianças de qualquer sexo, raça ou nacionalidade, de 7 a 14 annos de idade. Não terão ingresso nas escolas mixtas, alumnos do sexo masculino, maiores de 14 anos.

$\S$ único - A matricula será feita verbalmente ao professor, pelos pais ou tutores dos candidatos ou por estes. Não serão matriculados os candidatos que soffrerem de moléstias contagiosas;

Art. $7^{\circ}$ - O anno lectivo terá início no primeiro dia util do mês de Março e será encerrado depois dos exames, que serão feitos na segunda quinzena do mês de Dezembro.

Art $8^{\circ}$ - O horario das escolas será das 9 ás 11 e das 13 ás 16 horas.

Art. $9^{\circ}$ - Em cada escola haverá três livros, sendo um para a matricula dos alumnos, um para as actas de exame e um para a carga do material existente (REGULAMENTO DAS ESCOLAS MUNICIPAIS DE BAGÉ apud BICA; CORSETTI, 2016. p. 316 -317).

Podemos notar que, nos artigos arrolados acima, existem diversas preocupações quanto à necessidade da expansão do ensino primário no município como também nos distritos rurais com mais de 50 crianças, preocupação com a frequência escolar, com a infraestrutura das escolas, com a tipologia do ensino, em relação à idade dos alunos, sobre as condições de saúde das crianças para o ingresso nas escolas, sobre o período e o horário das aulas. Presume-se, então, que este regulamento foi influenciado pelos princípios republicanos, visto que já em seu primeiro capítulo

\footnotetext{
${ }^{5}$ Em seu estudo de doutorado, Corsetti (1998) defende em seu trabalho, os princípios da Política e da Organização Educacional, bem como, as características da Escola Pública no Rio Grande do Sul na Primeira República, portanto, na análise do Regulamento das Escolas Municipais de Bagé, percebemos as influências ideológicas do pensamento republicano em todos os seus capítulos. Neste sentido, afirmamos que na composição deste Regulamento, Carlos Cavalcanti Mangabeira inspirou-se nestes preceitos para a composição da primeira política pública para a educação primária municipal de Bagé.
}

Quaestio, Sorocaba, SP, v. 20, n. 1, p. 91-112, abr. 2018 
BICA, Alessandro Carvalho. A organização da Instrução Pública Municipal na década de 1920 no Município de Bagé/RS.

encontramos ideais defendidos por estes educadores. Sobre o estabelecimento dos regulamentos, Corsetti (1998, p. 284-286) afirma:

Os regulamentos e regimentos escolares, pelo conjunto de determinações que encerram, possibilitam a percepção da ação governamental num plano muito específico, ou seja, o interior da escola. A orientação positivista que norteou a ação dos republicanos gaúchos garantiu que esses instrumentos se transformassem em mais uma peça importante da engrenagem educacional, [...]. Devemos ressaltar inicialmente que essas regulamentações expressaram, nas suas diversas determinações, a forma como os elementos integrantes da política educacional do Estado gaúcho, - diríamos também dos municípios -, no tocante à escola pública, se realizam concretamente, evidenciando a tradução, na prática, dos pressupostos políticos e educacionais defendidos pelos republicanos (Grifos nossos).

No segundo capítulo do Regulamento das Escolas Municipais de Bagé, observam-se as preocupações em relação aos Programas de Ensino das escolas primárias, o artigo $10^{\circ}$ deste regulamento, determina que: O programma de ensino será organizado pelo inspector escolar $e$ por uma commissão de professores do Collegio Elementar, convidada pelo Intendente; é perceptível a anuência dada à figura do Inspetor escolar e aos professores do Colégio Elementar na organização do programa de ensino, isto é, na escolha técnica e qualificada dos programas escolares. Percebe-se novamente, os preceitos republicanos relativos à unidade administrativa e pedagógica do ensino presentes na configuração deste regulamento.

Art. $12^{\circ}$ - São exigidas as condições seguintes para ser professor:

c) Ter necessária habilitação, julgada por uma commissão examinadora, escolhida pelo intendente e presidida pelo Inspector, no exame a que será submetido.

Art. $13^{\circ}$ - Todos os professores teem por dever:

b) cumprir, rigorosamente, o programma de ensino;

c) Fazer sentir aos chefes de familia, em palestra ou por qualquer outro meio de propaganda, o mal do analphabetismo, incutindo-lhes no espirito de manterem seus filhos á escola;

d) Providenciar para que seja içada a bandeira nacional nos dias feriados pela República e pelo Estado, encarregando dessa o alumno mais applicado;

f) Ser delicado e bem para os alumnos, tratando os com maior carinho e fazendo-lhes comprehender que seu educador é um amigo e protector;

g) Não applicar castigos corporaes, nas faltas que forem commetidas, impondo, sómente, penas de tarefas escriptas, que redundem em proveito dos alumnos;

h) Apresentar todos os mêses mappa de matricula e frequencia dos alumnos, afim de receber seus vencimentos no thesouro municipal (REGULAMENTO DAS ESCOLAS MUNICIPAIS DE BAGÉ apud BICA; CORSETTI, 2016, p. 317-318).

Este capítulo revela as preocupações da municipalidade em relação aos deveres de seus professores, estes elementos que ocupariam o quadro docente do município deveriam ser pessoas idôneas, habilitadas para ocupar a função, contratadas por concurso, além de serem capazes de possibilitar as melhores condições para o ensino de seus alunos. 
BICA, Alessandro Carvalho. A organização da Instrução Pública Municipal na década de 1920 no Município de Bagé/RS.

Na letra $\mathbf{C}$ do Artigo 13, nota-se claramente a intenção da municipalidade em manifestar a preocupação em combater o analfabetismo através dos discursos do professor, confirmando assim a ideia defendida pelos republicanos da década de 1920, que as mazelas sociais eram causadas pela falta e pelo abandono das crianças das escolas (BICA; CORSETTI, 2016).

A preocupação com o imaginário republicano e com a absorção dos rituais e símbolos cívicos do novo regime também é preconizada neste capítulo, fazendo da escola pública o lócus primordial e eficaz para a assimilação dos valores da modernidade republicana.

$\mathrm{Na}$ letra $\mathbf{F}$ do mesmo artigo, menciona-se o tipo de conduta a ser seguida pelos professores, podemos aferir que eles seriam brandos nas suas ações e suaves no trato e/ou castigos com seus alunos. Essa afirmação pode ser contemplada quando se observa o item subsequente, onde ficam proibidos os castigos corporais e impondo somente aos alunos tarefas escritas de cunho educativo. Pode-se pensar então, que estas ações serviriam para que o professor estabelece-se uma relação de respeito mútuo com seus alunos (BICA; CORSETTI, 2016).

O capítulo IV - Inspetoria possui dois artigos principais, estes comentam sobre a importância do papel educacional do Inspetor, que seria o agente responsável pela feitura dos relatórios quantitativos e qualitativos da educação municipal, bem como, reafirma o papel de examinador nas bancas finais, da escritura dos mapas de matrículas das escolas urbanas e rurais, além de propor a nomeação e a exoneração de professores ao Intendente municipal (BICA; CORSETTI, 2016).

O penúltimo capítulo deste Regulamento é extremamente importante, porque trata dos vencimentos do Inspetor e dos professores do município, traduzindo as diferenças entre professores das escolas menores e maiores, bem como, sobre o sistema de bonificação dados aos professores municipais. Como se observa abaixo:

Dos vencimentos do Inspector e professores

Art. $17^{\circ}$ - São fixados, mensalmente, os vencimentos do inspector, em 200\$000; dos professores que leccionarem de 15 a 25 alumnos, em 150\$000; dos que leccionarem de 26 a 40 alumnos, em $200 \$ 000$.

$\S$ único - O inspector terá mais uma diária arbitrada pelo intendente, quando no interior do municipio, em serviço de seu cargo.

Art. $19^{\circ}$ - Será concedida uma gratificação especial, no fim do anno lectivo, aos professores que provarem, mediante attestado do inspector, do sub-intendente, dos pais dos alumnos ou de outras pessoas gradas, os seus esforços pelo ensino e pelo maior numero de educandos, a qual será fixada pelo intendente (REGULAMENTO DAS ESCOLAS MUNICIPAIS DE BAGÉ apud BICA; CORSETTI, 2016, p. 318-319). 
BICA, Alessandro Carvalho. A organização da Instrução Pública Municipal na década de 1920 no Município de Bagé/RS.

Especificamente em relação aos vencimentos dos professores das escolas municipais, podemos fazer a seguinte alusão com a prática usada pelos republicanos gaúchos na configuração salarial dos colégios estaduais em relação as suas entrâncias, isto significa afirmar que, quanto maior o colégio ou escola, maior o salário dos professores. Nestes termos ainda, entendemos que havia também uma cooptação política do professorado pelo Intendente Municipal, geralmente as escolas municipais que tinham uma maior frequência localizam-se na Zona Urbana do $1^{\circ}$ Distrito de Bagé, e as que possuíam menor frequência na Zona Rural, sendo assim, havia de certa forma uma diferenciação salarial e social dos professores na esfera municipal, esta mesma ação acontecia no plano estadual em relação aos professores das zonas urbanas e rurais (CORSETTI, 1998).

Portanto, pode-se concluir que, além de promover a estruturação do ensino primário público, o Regulamento das Escolas Municipais de Bagé promoveu a procura por novos alunos e consequentemente, a busca no aumento do número de matrículas por parte dos professores, visto que este empenho "pedagógico" poderia recompensá-los com uma maior remuneração financeira. Este fato nos permite afirmar que os professores que possuíam mais alunos e que demonstrassem mais esforços seriam premiados pela comunidade escolar, bem como, pela intendência municipal.

Quanto ao capítulo VII, que faz referência as Disposições Finais, destacamos os seguintes artigos:

Art. $20^{\circ}$ - Fica isento de impostos municipais, o chefe de família que tiver tres filhos frequentando, com assuididade, as aulas, de accordo com a autorização que opportunamente será solicitada ao Conselho.

Art. $21^{\circ}$ - Serão concedidos premios, pelo intendente ou por outras pessoas que visarem o mesmo objetivo, aos alumnos que demonstrarem melhor aproveitamento nos exames finais.

Art. $22^{\circ}$ - O municipio fornecerá ás crianças reconhecidamente pobres, o material que for necessario para seu ensino.

Art. $25^{\circ}$ - A municipalidade subvencionará qualquer escola que ministre ensino gratuito, justificados a frequencia e o aproveitamento dos alumnos.

Art. $26^{\circ}$ - Na sede do municipio, reconhecida a necessidade, serão creados grupos escolares dirigidos por três professores. As suas aulas funcionarão pela manhã, á tarde e á noite (REGULAMENTO DAS ESCOLAS MUNICIPAIS DE BAGÉ apud BICA; CORSETTI, 2016, p. 319).

Neste capítulo, podemos concluir que a municipalidade pretendia assegurar em seu Regulamento todo um aparato financeiro para manter as crianças nas escolas municipais, demonstrando a preocupação em garantir às famílias numerosas a isenção de impostos e a 
BICA, Alessandro Carvalho. A organização da Instrução Pública Municipal na década de 1920 no Município de Bagé/RS.

permanência de seus filhos na escola, evitando assim, o abandono e a evasão escolar e diminuindo os índices de analfabetismo do município de Bagé.

Outra questão observada que se impõe no Regulamento possui relação direta à oficialização dos prêmios por mérito aos alunos que obtivessem melhor destaque nos exames finais. Neste sentido, Dalabrida $(2002$, p. 6) afirma que esta prática era comum desde os tempos coloniais na educação brasileira:

A "digna emulação" era incentivada sutilmente nas classes ginasiais, estabelecendo um clima de constante superação entre todos os alunos, mas particularmente entre internos e externos. A emulação estava ligada ao sistema de premiação, que concedia solenemente recompensas aos melhores alunos no final do ano letivo e a cada bimestre (Grifos nossos).

Quanto ao Art. 26 , nota-se a intenção da criação de grupos escolares na cidade de Bagé, demonstrando assim a relação com os ideais republicanos e com as perspectivas de modernização da sociedade brasileira (BICA; CORSETTI, 2016).

Sem dúvida alguma, o estabelecimento e as imposições contidas no Regulamento das Escolas Municipais editado pela Intendência Municipal de Bagé no ano de 1925 promoveram as primeiras reformas educacionais na cidade e organizaram a Educação Municipal.

Compreendendo que este movimento inaugurado pela Intendência Municipal na gestão de Carlos Mangabeira tinha como propósito estabelecer o papel regenerador da educação e a implantação da organização e regularização da Educação Municipal, este movimento trouxe o conjugamento dos ideais republicanos da Primeira República.

Outra preocupação observada no processo da expansão do ensino primário foi à questão da infraestrutura interna das escolas municipais, com a disposição de materiais pedagógicos e símbolos pátrios e cívicos, medida esta concernente a manutenção dos preceitos republicanos, como afirma o Relatório do Inspetor Escolar presente no interior do Relatório da Intendência Municipal de Bagé do ano de 1926 (p. 70): "Foi distribuído pelas diversas aulas, [...] o seguinte material escolar: 72 cadeiras, 20 bandeiras nacionaes, 20 escudos Rio-grandenses e 16 quadros negros".

Ademais, percebeu-se a presença dos discursos médicos-higiênicos na fiscalização das escolas existentes no município de Bagé, como apresentado pelo Relatório do Inspetor Escolar do ano de 1926 (p. 70): “Este serviço tem sido feito pela Diretoria de Hygiene, a qual tem prestado forte concurso à instrucção, quer na inspecção das escolas particulares, quer na dos professores e 
alumnos das escolas publicas”. Este movimento, só foi possível, após a criação do Regulamento de Higiene no ano de 1925 pela Intendência Municipal de Bagé.

Sobre a importância dos discursos médicos e sobre o papel do processo higienizaçãoescolarização na Primeira República que resultaria na promoção da civilidade tão desejada pelos dirigentes republicanos, Stephanou (2005, p.148) faz a seguinte afirmação:

A medicina vinha a cumprir um papel fundamentalmente preventivo. As doenças da civilização moderna ofereciam um campo enorme para as ações sanitárias. Os médicos apresentaram-se como uma espécie de mediadores, aqueles que, propondo medidas de ordenamento do espaço e purificação do meio, conduziriam a uma sociedade sadia e positivamente civilizada. A degeneração poderia ser contornada. A enfermidade dos corpos e da sociedade cederia lugar à saúde e à vida. Fazia-se mister, contudo, garantir o espaço para a atuação educativa e saneadora da medicina [...] A educação aparecerá como aquela tarefa afinada com a missão da medicina preventiva. Mas à medicina social, profilática por excelência, incumbiam também ações corretivas e ortopédicas (Grifos nossos).

Além da preocupação com as condições higiênicas das escolas municipais, outro ponto destacado no Relatório do Inspetor Escolar refere-se às condições arquitetônicas dos espaços escolares das aulas municipais, como se pode perceber no trecho abaixo:

\begin{abstract}
Antes de entrar na explanação dos trabalhos escolares, desejo fazer algumas considerações sobre as casas em que funccionam as aulas, chamando a attenção de V. S. para este ponto que julgo de real importância. Como V. S. teve ocasião de observar pessoalmente a maioria destas casas, embora não sejam desprovidas dos requisitos hygienicos, contudo não sendo construídas para este fim, apresentam senões difficeis de serem corrigidos, já pela propria edificação, algumas vezes, em desaccordo com os preceitos pedagogicos, já por se tratarem de edifícios particulares. Estas e outras inconveniencias que soem acontecer freqüentemente seriam sanadas pelo modo como prevê o art. $4^{06}$ do regulamento elaborado por V. S., isto é, pela construcção de casas apropriadas. As vantagens d'ahi resultantes seriam innumeras, pois além do municipio pagar pelo capital empregado, juros inferiores aos alugueis actuaes, desappareceriam as inconveniencias de mudanças, transferencias, etc., facilitando ainda a creação de grupos escolares o que muito contribuiria para a maior diffusão do ensino (RELATÓRIO DO INSPETOR ESCOLAR, 1927, p. 50, grifos nossos).
\end{abstract}

Segundo Viñao Frago (1998, 2005), o espaço escolar foi sendo pensado para ser laboratorial, disciplinador e difusor de práticas higiênicas e moralizantes. Além de possibilitar o

\footnotetext{
${ }^{6}$ O Inspetor Escolar ao fazer alusão ao Regulamento das Escolas Municipais refere-se especificamente neste sentido ao texto do Art. $4^{\circ}$ deste regulamento, que afirma: As escolas funccionarão em casas de aluguel, arrendadas ou offerecidas pelos proprietários, dotando-as a municipalidade de todas as condições hygienicas, até que sejam construidos edificios próprios. O mobiliario e o material necessario para o ensino, serão fornecidos pela intendência (Grifos nossos).
} 
aperfeiçoamento do espírito, o doutrinamento do corpo, e se necessário para a inculcação dos novos saberes do universo escolar moderno e republicano.

No processo de análise das fontes levantadas nesta pesquisa no contexto das reformas municipais empreendidas na gestão do Intendente Municipal Carlos Mangabeira, verificou-se a importância conferida à figura do Inspetor Escolar, Waldemar Amorety Machado ${ }^{7}$, na consecução do projeto modernizador pensado pela Intendência Municipal.

Portanto, no processo de expansão do ensino primário municipal as preocupações atinentes aos esforços da municipalidade foram amplamente defendidas pelo Inspetor Escolar, como se pode observar em seu Relatório:

Proseguindo na execução do programma administrativo, a que se produz o esclarecido governo de V. S., têm-se empregado todos os recursos accessíveis, para que o ensino primario tenha a mais ampla diffusão neste municipio. [...]. Comtudo, se senões ainda existem, é porque certamente, todas as questões que surgem, quando se trata de resolver tão magno, quão momentoso problema, não pertencem ao curto espaço de tempo, que medeia uma gestão administrativa, mas reclamam demorado estudo e constantes esforços, que visem, ao menos, por em equação o problema, para os trabalhos de cada anno, sejam a continuação dos do precedente, seguindo deste modo por caminho recto e seguro ate o fim collimado, o que não só evita o destruir para recomeçar, como ainda facilita as futuras administrações. Para este ponto fundamental, tem-se feito convergir todos os esforços, afim de formar um systema educativo, capaz de obter o maximo de resultados práticos e immediatos (RELATÓRIO DO INSPETOR ESCOLAR, 1928, p. 33-34, grifos nossos).

Ao analisarmos a citação acima, observamos a importância da figura do Inspetor Escolar, como agente da municipalidade com poder para fazer cumprir os programas de transformações pensados para as escolas primárias municipais. Por outro lado, o próprio inspetor escolar assumia as exigências descritas no Regulamento das Escolas Municipais de Bagé ${ }^{8}$ referentes ao seu cargo, além de afirmar que a expansão do ensino primário fazia parte do processo de organização do systema educativo municipal e capaz de obter o maximo de resultados práticos e immediatos para a educação pública primária.

\footnotetext{
${ }^{7}$ O professor Waldemar Amorety Machado era diretor do Colégio São Luiz Gonzaga na época de sua nomeação para Inspetor Escolar, era reconhecido como um educador dedicado nas causas educacionais. Mesmo após o fim da Primeira República dedicou-se ao magistério no município de Bagé.

8 No Regulamento das Escolas Municipais de Bagé, os capítulos da Inspetoria e Fiscalização do Ensino, determinavam entre outras coisas, que o Inspetor de Ensino: deveria apresentar ao intendente um relatório minucioso do trabalho nas escolas, propor e tomar medidas convenientes para o bom funcionamento das escolas; Propor a remoção de professores que tivessem pouca frequencia de alunos e suspender professores que não atendessem as funções de seu ofício. Todas essas decisões deveriam ser comunicadas ao Intendente Municipal.
} 
BICA, Alessandro Carvalho. A organização da Instrução Pública Municipal na década de 1920 no Município de Bagé/RS.

De acordo com Faria Filho (2000), os Inspetores de Ensino imprimiam suas observações dos acontecimentos do cotidiano escolar, possibilitavam o controle, como possíveis intervenções nas atividades desenvolvidas nas escolas. Em outras palavras, os relatórios produzidos concediam à Intendência Municipal uma maneira de fiscalizar as atividades dos profissionais que atuavam nos estabelecimentos de ensino, de forma a manter sempre vivo os interesses da municipalidade.

Observadas as especificidades do papel do Inspetor Escolar no processo da expansão do ensino primário municipal, outros dados encontrados no Relatório de Waldemar Amorety Machado merecem ainda ser analisados no corpo deste trabalho. Sobre o aumento da oferta do ensino primário público municipal, encontramos a seguinte afirmação no Relatório apresentado no ano de 1928:

GRUPO ESCOLAR DE S. MARTIM - Attendendo ao prospero desenvolvimento deste povoado visinho, [...] foi por acto $n^{\circ} 353$, de 11 de abril deste anno, creado um grupo escolar nessa localidade. Este grupo funcciona três vezes, sendo uma dellas á noite, o que favorece consideravelmente a frequencia as aulas, especialmente por parte daquelles, que pelos afazeres quotidianos, não podem subordinar-se ao horario comum. Além deste grupo foram creadas, por acto $\mathrm{n}^{\mathbf{0}} 354$ e na mesma data, as aulas municipaes localizadas nos logares denominados Boa Vista, Santa Tecla, Villa Alegre, Lageado, Povo Novo e Xarqueada Industrial. Foi ainda por acto $\mathbf{n}^{\mathbf{0}} 360$ de 31 de maio, creada outra aula no logar denominado "Igrejinha", sendo nomeada para Regel-a, por acto ${ }^{\circ} 361$ da mesma data, a prof ${ }^{a}$ Alzira Cazarré (RELATÓRIO DO INSPETOR ESCOLAR, 1928, p. 36, grifos nossos).

Nesta passagem do Relatório, observa-se que, além da preocupação existente no processo desta expansão, havia também a preocupação com o gerenciamento da educação primária municipal, reunindo as aulas existentes no distrito de São Martim, e constituindo assim o primeiro grupo escolar da cidade de Bagé, segundo Souza (1998, p. 45) esta prática era comum nos governos republicanos "Foram criados os grupos escolares, por via de um artifício legal segundo o qual, havendo mais de uma escola no raio de obrigatoriedade escolar, o governo poderia autorizá-las a funcionar em um só prédio”. Neste sentido, afirma-se que a educação passou a ser considerada instrumento essencial na preparação do cidadão republicano para o trabalho e para a prática política e, também, emergiu a crença de que só pela educação popular as dificuldades econômico-financeiras seriam superadas. Em outros termos, na afirmação de Nagle (2001, p. 149): 
[...] firma-se o princípio de que a educação popular é a pedra angular sobre que repousa a estrutura toda da organização social', ou melhor, chega-se, por essa via, à conclusão de que a estrutura política, econômica e social da Nação apresenta-se instável porque sobre ela pesa a grande massa de analfabetos, que lhes ameaça as bases.

Portanto, os discursos proferidos pelo Inspetor Escolar, bem como pelo Intendente Municipal, revelam que neste processo de expansão da educação primária municipal ocorresse os primeiros grandes avanços sociais na educação popular, como observamos no enunciado abaixo:

\begin{abstract}
Instrucção Publica - Se em todos os departamentos da administração municipal tem havido a preoccupação de conservar melhorando, de certo na parte referente á instrucção publica, tenho procurado empregar todos os esforços para que cada vez mais se desenvolva este ramo do poder publico e que preoccupa enormemente todos os governos. É com desvanecimento que trago ao conhecimento do illustre Conselho Municipal, que a instrucção publica, no municipio, melhora consideravelmente n'uma affirmação iniludivel de que já a grande maioria dos Paes se preoccupa com a instrucção indispensavel de seus filhos (RELATÓRIO DA INTENDÊNCIA MUNICIPAL, 1928, p. 4, grifos nossos)
\end{abstract}

Primeiramente, no que tange à administração de Carlos Cavalcanti Mangabeira, o Intendente externalizou um princípio do positivismo importante nas administrações republicanas, neste sentido a preoccupação de conservar melhorando, sublinha em seu discurso alguns valores, tais como, idéia de progresso e ordem, do papel fundamental atribuído à ciência (via educação) e que o cientificismo, se expressa na crença na razão, isto é, que o conhecimento científico aparece como único conhecimento possível.

Sendo assim, os Relatórios Intendenciais analisados até este momento revelam que as ações empreendidas pela municipalidade entre os anos de 1925 a 1929 da gestão de Carlos Cavalcanti Mangabeira dinamizaram a educação primária municipal. Portanto, a organização educacional municipal de Bagé produziu uma série de determinações legais, como a existência do Inspetor Escolar, a contratação de professores, a expansão do número de aulas municipais para sede e a campanha do município, a subvenção para escolas particulares, a criação de grupos escolares e a compreensão da educação como um ramo da política pública municipal.

Ademais, o progresso quantitativo da Organização Educacional Municipal pode ser observado quando confrontamos os números da Instrução Pública Municipal da última gestão de Tupy Silveira (1921-1924) com a gestão de Carlos Mangabeira (1925-1928) no quadro abaixo: 
BICA, Alessandro Carvalho. A organização da Instrução Pública Municipal na década de 1920 no Município de Bagé/RS.

Quadro 1 - Instrução Pública Municipal (1921-1928)

\begin{tabular}{|c|c|c|c|c|c|c|c|c|}
\hline Aulas & 1921 & 1922 & 1923 & 1924 & 1925 & 1926 & 1927 & 1928 \\
\hline Estaduais & 02 & 02 & 02 & 02 & 02 & 02 & 02 & 02 \\
\hline Particulares & 25 & 28 & 28 & 35 & 14 & 14 & 14 & 14 \\
\hline Paroquiais & 03 & 03 & 03 & 03 & 03 & 02 & 02 & 02 \\
\hline Municipais & 06 & 06 & 06 & 06 & 14 & 18 & 18 & 21 \\
\hline Municipais Subvencionadas & 14 & 14 & 14 & 14 & 14 & 14 & 14 & 14 \\
\hline & 50 & 53 & 53 & 68 & 47 & 50 & 50 & 53 \\
\hline
\end{tabular}

Fonte: Quadro elaborado pelo autor a partir dos Relatórios Intendências.

Em relação aos dados quantitativos expostos pelo Quadro 1, observamos que a intervenção estadual no município de Bagé, sempre correspondeu a 14 (quatorze) subvenções às aulas municipais, 01 (um) Colégio Elementar e 01 (uma) escola isolada para o sexo masculino ${ }^{10}$. Durante a última gestão de Martim Silveira, houve um aumento gradual de $40 \%$ no oferecimento de escolas particulares. Em relação às escolas paroquiais e aulas municipais este percentual permaneceu igual entre os anos de 1921 a 1924.

Por outro lado, no período da gestão de Carlos Cavalcanti Mangabeira (1925-1928), observamos que o aumento gradual ocorrido na oferta de aulas da iniciativa privada no período de 1921 a 1924 teve uma queda percentual de 60\% no número de aulas oferecidas. Logo, a introdução da Organização Educacional Municipal, em 1925, promoveu um aumento na oferta de aulas públicas tuteladas pelo município em 250\%, isto é, de 06 aulas no ano de 1924 para 21 aulas no ano de 1928.

Além disso, no processo de expansão da intervenção municipal na Educação configurouse também a manutenção e o aumento das subvenções às escolas paroquiais e particulares, esta ação pode ser constatada quando observamos o quadro 2 sobre os números da intervenção municipal na Instrução Pública Municipal:

\footnotetext{
${ }^{9}$ É preciso afirmar que a partir do ano de 1916, o governo do Estado começou a subvencionar 14 aulas municipais. Neste sentido, os Relatórios Intendências ao apresentarem o número total de aulas municipais somavam as subvencionadas pelo Estado com as aulas mantidas pela Intendência.

${ }^{10}$ Cabe salientar que no processo de análise dos Relatórios Intendências da cidade de Bagé, percebeu-se que após o ano de 1920, existiam apenas duas ocorrências de aulas estaduais no município, umas delas referia-se ao Colégio Elementar e a outra a escola isolada do Professor Arthur Domingos Orfino. Especificamente ao Professor Arthur D. Orfino encontramos as primeiras referências sobre sua atuação no município de Bagé no Relatório da Instrução Pública do ano de 1912.
}

Quaestio, Sorocaba, SP, v. 20, n. 1, p. 91-112, abr. 2018 
BICA, Alessandro Carvalho. A organização da Instrução Pública Municipal na década de 1920 no Município de Bagé/RS.

Quadro 2 - Intervenção Municipal na Instrução Pública Municipal (1921-1928)

\begin{tabular}{|c|c|c|c|c|c|c|c|c|c|}
\hline \multicolumn{1}{|c|}{ Aulas } & 1921 & 1922 & 1923 & 1924 & 1925 & 1926 & 1927 & 1928 \\
\hline Particulares Subvencionadas & 03 & 03 & 03 & 03 & 03 & 03 & 03 \\
\hline Paroquiais Subvencionadas & 01 & 01 & 01 & 01 & 03 & 04 & 04 & 04 \\
\hline & 04 & 04 & 04 & 04 & 06 & 07 & 07 & 08 \\
\hline
\end{tabular}

Fonte: Quadro elaborado pelo autor a partir dos Relatórios Intendências.

Ao analisarmos o quadro acima, algumas observações podem ser feitas, entre elas, que a administração municipal no período de 1921 a 1928, pouco alterou o número de subvenções às escolas particulares, visto que havia um número significativo de escolas particulares na cidade de Bagé.

Porém, por outro lado, neste mesmo período ocorreram aumentos significativos nas subvenções municipais às escolas paroquiais, esta ação possivelmente demonstra a relação de cordialidade e convergências entre os republicanos bajeenses e as ordens católicas existentes na cidade, estes acordos diplomáticos são constatados por Corsetti (1998, p. 137) “A conciliação que se efetuou entre o Estado gaúcho e a Igreja Católica [...] possibilitou os favores mútuos com os quais as duas instituições marcaram sua trajetória na história rio-grandense".

Sendo assim, ao nos debruçarmos sobre as fontes examinadas, entendemos que no processo de expansão da Instrução Pública Municipal, ocorrido na cidade de Bagé entre os anos de 1925 a 1929, a gestão municipal de Carlos Cavalcanti Mangabeira imprimiu a cidade um novo reordenamento urbano e social em todos seus aspectos, porém, sua grande contribuição se verificou na configuração e na Organização Educacional Municipal.

Este movimento inaugurado na gestão intendencial de Carlos Mangabeira edificou um novo planejamento educacional e conferiu ao município de Bagé um quadro de mudanças significativas de ordem administrativa, estrutural, educacional e pedagógica.

Entretanto, estas mudanças também provocaram novas implicações educacionais na cidade, como a municipalização do Gymnasio Nossa Senhora Auxiliadora, o estabelecimento do Conservatório Municipal de Bagé e a construção da Praça de Desportos. 


\section{Referencias}

BAKOS, Margaret M. Política na Sala de Visitas (1897-1937). In: HISTÓRIA Geral do Rio Grande do Sul. Passo Fundo: Méritos, 2007. v. 3. República Velha (Tomo I).

BICA, Alessandro C.; CORSETTI, Berenice. Regulamento das Escolas Municipais do Município de Bagé/RS (1925). Revista História da Educação, Porto Alegre, v. 20, n. 48, jan./abr. 2016. p. 313-319.

CORREIO DO SUL. Bagé/RS, 18 abr. 1925.

CORREIO DO SUL. Bagé/RS, 09 maio 1925.

CORREIO DO SUL. Bagé/RS, 07 jun. 1925.

CORREIO DO SUL. Bagé/RS, 17 jun. 1925.

CORREIO DO SUL. Bagé/RS, 15 jul. 1925.

CORREIO DO SUL. Bagé/RS, 02 ago. 1925.

CORREIO DO SUL. Bagé/RS, 04 ago. 1925.

CORREIO DO SUL. Bagé/RS, 05 ago. 1925.

CORREIO DO SUL. Bagé/RS, 24 mar. 1926.

CORREIO DO SUL. Bagé/RS, 10 ago. 1927.

CORREIO DO SUL. Bagé/RS, 16 ago. 1927.

CORSETTI, Berenice. Controle e ufanismo. A Escola Pública no Rio Grande do Sul (1890-1930).

1998. Tese (Doutorado em Educação) - Faculdade de Educação, Universidade Federal de Santa Maria, Santa Maria, 1998.

CORSETTI, Berenice. Cultura política positivista e educação no Rio Grande do Sul/Brasil (1889/1930). Cadernos de Educação, Pelotas, n. 31, p. 55-69, jul./dez. 2008.

DALABRIDA, Norberto. Disciplina e devoção: o Ginásio Catarinense na Primeira República. In: CONGRESSO BRASILEIRO DE HISTÓRIA DA EDUCAÇÃO: História e memória da educação brasileira. 2. 2002. Anais... Rio Grande do Norte: Natal, 2002. Disponível em:

<http://www.sbhe.org.br/novo/congressos/cbhe2/pdfs/Tema3/3151.pdf>. Acesso em: 29 jun. 2013.

O DEVER. Bagé/RS, 09 maio 1925.

O DEVER. Bagé/RS, 04 ago. 1925.

O DEVER. Bagé/RS, 05 ago. 1925.

O DEVER. Bagé/RS, 19 ago. 1925.

O DEVER. Bagé/RS, 11 maio 1926.

O DEVER. Bagé/RS, 15 ago. 1926.

O DEVER. Bagé/RS, 29 dez. 1926.

O DEVER. Bagé/RS, 27 jan. 1927.

FARIA FILHO, L. M. Dos pardieiros aos palácios: cultura escolar e urbana em Belo Horizonte na Primeira República. Passo Fundo: UPF, 2000.

NAGLE, Jorge. Educação e sociedade na Primeira República. 2. ed. Rio de Janeiro: DP\&A, 2001.

Quaestio, Sorocaba, SP, v. 20, n. 1, p. 91-112, abr. 2018 
BICA, Alessandro Carvalho. A organização da Instrução Pública Municipal na década de 1920 no Município de Bagé/RS.

RELATÓRIO Intendencial de Carlos Cavalcanti Mangabeira apresentado ao Conselho Municipal em 20 de setembro de 1925. Bagé: Typografia Casa Maciel, 1925.

RELATÓRIO DO INSPETOR ESCOLAR 1926. In: RELATÓRIO Intendencial de Carlos Cavalcanti Mangabeira apresentado ao Conselho Municipal em 20 de setembro de 1926. Bagé: Typografia Casa Maciel, 1926.

RELATÓRIO DO INSPETOR ESCOLAR 1927. In: RELATÓRIO Intendencial de Carlos Cavalcanti Mangabeira apresentado ao Conselho Municipal em 20 de setembro de 1927. Bagé: Typografia Casa Maciel, 1927.

RELATÓRIO DO INSPETOR ESCOLAR 1928. In: RELATÓRIO Intendencial de Carlos Cavalcanti Mangabeira apresentado ao Conselho Municipal em 20 de setembro de 1928. Bagé: Typografia Casa Maciel, 1928.

RELATÓRIO DO INSPETOR ESCOLAR 1929. In: RELATÓRIO Intendencial de Alziro Marino apresentado ao Conselho Municipal em 20 de setembro de 1929. Bagé: Typografia Casa Maciel, 1929.

SILVA, Mozart Linhares da. Do império da lei às grades da cidade. Porto Alegre: EDIPUCRS, 1997.

SOUZA, Rosa Fátima de. Templos de civilização: a implantação da escola primária graduada no Estado de São Paulo (1890-1910). São Paulo: Fundação Editora da UNESP, 1998.

STEPHANOU, M. Discursos médicos e a educação sanitária na escola brasileira. In: STEPHANOU, M.; BASTOS, M. H. C. (Org.). Histórias e memórias da educação no Brasil. v. III: século XX. Petrópolis: Vozes, 2005, p. 142-164.

VIÑAO FRAGO, Antonio. Do espaço escolar e da escola como lugar: propostas e questões. In: VIÑAO FRAGO, Antonio; ESCOLANO, Augustín. Currículo, espaço e subjetividade: a arquitetura como programa. Rio de Janeiro: DP\&A, 1998. p. 59-139.

VIÑAO FRAGO, Antonio. Espaços, usos e funções: a localização e disposição física da direção escolar na escola graduada. In: BENCOSTA, Marcus Levy Albino (Org). História da educação, arquitetura e espaço escolar. São Paulo: Cortez, 2005. p. 15-47.

WEBER, Beatriz Teixeira. Códigos de posturas e regulamentação do convívio social em Porto Alegre no século XIX. 1922. Dissertação (Mestrado em História) - Curso de Pós-Graduação em História da UFRGS, Porto Alegre, 1992.

Alessandro Carvalho Bica

Universidade Federal do Pampa | Campus Bagé - Educação

Bagé | RS | Brasil. Contato: alessandro.bica@unipampa.edu.br. ORCID 0000-0003-2532-5007 